\title{
Differences in Physical and Psychological Condition, Sleeping Status and Menstruation-Related Symptoms before and after Smartphones Use in Young Female Students in Japan
}

\author{
Yukie Matsuura1*, Takane Morita², Momoko Sekimoto², Ayaka Maeda ${ }^{3}$, Toshiyuki Yasui1 \\ ${ }^{1}$ Department of Reproductive and Menopausal Medicine, Graduate School of Biomedical Sciences, Tokushima University, \\ Tokushima, Japan \\ ${ }^{2}$ Nursing Department, Tokushima Red Cross Hospital, Tokushima, Japan \\ ${ }^{3}$ Nursing Department, Tokushima University Hospital, Tokushima, Japan \\ Email: ${ }^{\star}$ y.matsuura@tokushima-u.ac.jp
}

How to cite this paper: Matsuura, Y., Morita, T., Sekimoto, M., Maeda, A. and Yasui, T. (2020) Differences in Physical and Psychological Condition, Sleeping Status and Menstruation-Related Symptoms before and after Smartphones Use in Young Female Students in Japan. Health, 12, 407-424. https://doi.org/10.4236/health.2020.124033

Received: March 16, 2020

Accepted: April 24, 2020

Published: April 27, 2020

Copyright $\odot 2020$ by author(s) and Scientific Research Publishing Inc. This work is licensed under the Creative Commons Attribution International License (CC BY 4.0).

http://creativecommons.org/licenses/by/4.0/ (c) (i) Open Access

\begin{abstract}
Smartphones use for a long period of time can cause health problems including physical condition, psychological condition and sleeping status. In addition, smartphones use may affect menstruation related symptoms. This study was conducted using a self-administered questionnaire between June and November in 2016 to clarify the differences in physical and psychological condition, sleeping status and menstruation-related symptoms before and after starting to use smartphones in female university students in Japan. We recruited 273 female nursing students and the response rate was $95.2 \%$. We found significant changes after starting to use smartphones regarding eyestrain $(\mathrm{p}<0.001)$, posture $(\mathrm{p}=0.002)$, stiffness of neck, back and shoulders $(\mathrm{p}<$ $0.001)$, level of outdoor activity ( $\mathrm{p}<0.001)$, difficulty concentrating $(\mathrm{p}<0.001)$, lack of motivation $(\mathrm{p}<0.001)$, and sensitivity to stress $(\mathrm{p}=0.005)$. Moreover, we also found that fatigue before menstruation and headache/low back pain during menstruation were higher after starting to use smartphones. The proportions of students with irritability and depressive feeling as emotional premenstrual symptoms appeared higher after starting to use smartphones. These results imply that young women should refrain from using smartphones if they have visual display terminal-related symptoms, disturbance of sleep pattern and menstruation-related symptoms before and during menstruation.
\end{abstract}

\section{Keywords}

Smartphone, Visual Display Terminal, Menstruation-Related Symptoms, Physical and Psychological Symptoms, Young Students 


\section{Introduction}

Electronic devices with visual displays are now being used by people all over the world. Among such devices, smartphones have become universally available due to their compact nature. In Japan, the household ownership rate for smartphones increased from $49.5 \%$ in 2012 to $75.1 \%$ in 2017 [1], and the individual ownership rates for smartphone in 2017 were $94.5 \%$ for people in their 20 's and $79.5 \%$ for people of 13 to 19 years of age [2].

Smartphones use for a long period of time can cause visual display terminal (VDT) syndrome. It has been reported that smartphones use was strongly associated with dry eye disease in children [3] and that smartphones use can aggravate asthenopia and induce tear film instability and oxidative stress in the tears and at the ocular surface [4]. Studies have shown that VDT users might be at increased risk of developing musculoskeletal symptoms [5] [6] and mental and physical health problems [7]. Recent studies have shown that smartphones operation with one hand caused greater upper trapezius pain [8] and overuse of smartphones are associated with anxiety in students [9] [10]. It has been reported that performing an exciting VDT task with a bright display suppressed nocturnal changes in melatonin level and physiological indicators of the human biological clock [11]. It has also reported that the use of light-emitting electronic devices for reading before bedtime prolonged the time it takes to fall asleep, delayed the circadian clock, and reduced melatonin levels [12]. Circadian rhythm disorders can cause not only sleep disturbance but also hypertension, diabetes mellitus and obesity [13] [14]. Recently, it was found that blue-enriched light exposure acutely alters glucose metabolism and sleepiness [15].

On the other hand, menstruation-related symptoms such as premenstrual symptoms and menstrual pain are now focusing on the diseases to influence to their quality of health for young female generation. Premenstrual symptoms are that various physical and psychological uncomfortable symptoms occur in women before menstruation, and their pathological state is called premenstrual syndrome (PMS). It has been reported that secretion of melatonin in the luteal phase was less than that in the follicular phase in women with PMS [16], and healthy women are likely to have insomnia due to a decrease in melatonin secretion before menstruation [17]. Disturbance of circadian rhythm by using electronic devices may affect menstruation-related symptoms including premenstrual symptoms and menstrual pain in young women, but this association has not been clarified.

The purpose of this study was to clarify the differences in physical and psychological condition, sleeping status and menstruation-related symptoms before and after starting to use smartphones in female university students in Japan.

\section{Materials and Methods}

We conducted this cross-sectional survey between June and November in 2016. We recruited 273 female nursing students at a university in Japan. The students 
were asked to complete a questionnaire at the end of a lecture, and the questionnaires were collected on the same day. Informed consent was obtained prior to participation in the study. This study was approved by the Ethics Committee of Tokushima University Hospital (approval number: 2595).

\subsection{Questionnaire}

We designed a self-administered questionnaire (appendix) that took about 15 minutes to complete. The first part of the questionnaire consisted of questions on age, body height and weight, and menstrual status including age of menarche, menstrual regularity, menstrual amount and duration, menstrual cycle and presence of dysmenorrhea. The second part consisted of questions on 1) age when starting to use smartphones and number of hours used each day, 2) differences in physical conditions (appetite, body weight, constipation, eyestrain, eyesight, posture, stiffness, dryness of eyes, dizziness, ringing in the ears, nausea and headache and activity such as increase in time spent sitting or lying after starting to use smartphones, degrees of deterioration in eyesight and decline in physical strength) before and after starting to use smartphones, 3) differences in psychological conditions (irritability, difficulty concentrating, lack of motivation, sensitivity to stress) before and after starting to use smartphones, 4) differences in sleeping status before and after starting to use smartphones, 5) differences in menstrual status and menstruation-related symptoms such as premenstrual symptoms (irritability, depression, emotional instability, difficulty concentrating, breast tenderness, fatigue, rough skin, hypersomnia and increase in body weight), and menstrual pain (abdominal pain, headache and low back pain) before and after starting to use smartphones and 6) strategies for coping with various symptoms (decreasing the duration of use, frequent breaks, applying eye lotion, using protective eyeglasses, using in a place with sufficient brightness, not using before sleeping, visiting hospitals, taking medications, doing eye massages or eye exercises, looking far away, viewing the screen from a distance and using with eyes closed).

\subsection{Statistical Analysis}

Each categorized variable is expressed as a number with percentage. The significance of differences in physical and psychological conditions, sleeping status, and menstrual conditions before and after starting to use smartphones was evaluated by the chi-square test. Statistical analyses were carried out using SPSS version 20 for Windows. All p values are two-tailed and those less than 0.05 were considered statistically significant.

\section{Results}

\subsection{Background Characteristics of the Participants}

The response rate for the survey was $95.2 \%$ (260/273). The mean age \pm standard deviation of the students was $20.0 \pm 1.9$ years. The results showed that $2.4 \%$ of 
the students started to use smartphones in elementary school (6 - 12 years old), $12.5 \%$ in junior high school (12 - 15 years old), $63.5 \%$ in high school (15 - 18 years old) and $21.6 \%$ in university. The duration spent using smartphones were 3 - 5 hours per day for $36.5 \%$ of the students, less than 3 hours for $29.4 \%, 5-7$ hours for $19.6 \%, 7$ - 9 hours for $11.1 \%$ and more than 9 hours for $3.5 \%$.

\subsection{Differences in Physical Conditions before and after Starting to Use Smartphones}

There were significant differences before and after starting to use smartphones in eyestrain, posture, stiffness of the neck, back and shoulders, and level of outdoor activity on a holiday (Table 1). Degrees of deterioration in eyesight were severe in $12.3 \%$ of the students, moderate in $33.5 \%$ and slight in $28.8 \%$. The

Table 1. Differences in physical conditions before and after starting to use smartphones.

\begin{tabular}{|c|c|c|c|c|c|c|}
\hline \multirow[b]{2}{*}{ Eyestrain } & \multirow[b]{2}{*}{ no } & \multicolumn{2}{|c|}{$\begin{array}{l}\text { Before using } \\
\text { smartphones }\end{array}$} & \multicolumn{2}{|c|}{$\begin{array}{l}\text { After starting to } \\
\text { use smartphones }\end{array}$} & \multirow{2}{*}{$\begin{array}{l}\text { P value } \\
<0.001\end{array}$} \\
\hline & & 78 & $(30.0)$ & 14 & $(5.4)$ & \\
\hline & a little & 109 & $(41.9)$ & 80 & $(30.8)$ & \\
\hline & to some extent & 56 & $(21.5)$ & 108 & $(41.5)$ & \\
\hline & severe & 5 & $(1.9)$ & 45 & $(17.3)$ & \\
\hline & missing & 12 & $(4.6)$ & 13 & $(5.0)$ & \\
\hline \multirow[t]{4}{*}{ Posture } & cannot say & 87 & $(33.5)$ & 63 & $(24.2)$ & 0.002 \\
\hline & good & 26 & $(10.0)$ & 14 & $(5.4)$ & \\
\hline & bad & 137 & $(52.7)$ & 177 & $(68.1)$ & \\
\hline & missing & 10 & $(3.8)$ & 6 & $(2.3)$ & \\
\hline \multirow{5}{*}{$\begin{array}{l}\text { Stiffness of the neck, } \\
\text { back and shoulders }\end{array}$} & no & 57 & $(21.9)$ & 29 & $(11.2)$ & $<0.001$ \\
\hline & a little & 80 & $(30.8)$ & 56 & $(21.5)$ & \\
\hline & to some extent & 78 & $(30.0)$ & 78 & $(42.7)$ & \\
\hline & severe & 35 & $(13.5)$ & 59 & $(22.7)$ & \\
\hline & missing & 10 & $(3.8)$ & 5 & $(1.9)$ & \\
\hline \multirow{5}{*}{$\begin{array}{c}\text { Level of activity on a } \\
\text { holiday }\end{array}$} & no & 41 & $(15.8)$ & 32 & $(12.3)$ & $<0.001$ \\
\hline & a little & 68 & $(26.2)$ & 63 & $(24.2)$ & \\
\hline & to some extent & 91 & $(35.0)$ & 101 & $(38.8)$ & \\
\hline & quite & 44 & $(16.9)$ & 54 & $(20.8)$ & \\
\hline & missing & 16 & $(6.1)$ & 10 & $(3.8)$ & \\
\hline \multirow[t]{5}{*}{ Constipation } & no & 131 & $(50.4)$ & 125 & $(48.1)$ & ns \\
\hline & a little & 60 & $(23.1)$ & 66 & $(25.4)$ & \\
\hline & moderate & 40 & $(15.4)$ & 46 & $(17.7)$ & \\
\hline & severe & 14 & $(5.4)$ & 15 & $(5.8)$ & \\
\hline & missing & 15 & $(5.8)$ & 8 & $(3.1)$ & \\
\hline
\end{tabular}

Number (\%), ns: not significant. 
proportion of students who increased time spent sitting or lying after starting to use smartphones was $48.1 \%$. Degrees of decline in physical strength after starting to use smartphones were severe in $3.1 \%$ of the students, moderate in $16.1 \%$ and slight in $43.1 \%$. Physicals symptoms that occurred after starting to use smartphones were dryness of eyes (59.2\% of the students), dizziness (7.3\%), ringing in the ears (5.0\%), nausea (1.9\%) and headache (26.7\%).

\subsection{Differences in Psychological Conditions before and after Starting to Use Smartphones}

The proportions of students with difficulty concentrating, lack of motivation and sensitivity to stress were significantly higher after starting to use smartphones (Table 2).

\subsection{Differences in Sleeping Status before and after Starting to Use Smartphones}

There were significant differences before and after starting to use smartphones in the time spent using smartphones before sleeping, bedtime, sleeping hours,

Table 2. Differences in psychological conditions before and after starting to use smartphones.

\begin{tabular}{|c|c|c|c|c|c|c|}
\hline \multirow[b]{2}{*}{ Irritability } & \multirow[b]{2}{*}{ none } & \multicolumn{2}{|c|}{$\begin{array}{l}\text { Before using } \\
\text { smartphones }\end{array}$} & \multicolumn{2}{|c|}{$\begin{array}{l}\text { After starting to } \\
\text { use smartphones }\end{array}$} & \multirow{2}{*}{$\frac{\text { P value }}{\text { ns }}$} \\
\hline & & 78 & $(30.0)$ & 61 & $(23.5)$ & \\
\hline & rarely & 129 & $(49.6)$ & 142 & $(54.6)$ & \\
\hline & frequently & 46 & $(17.7)$ & 47 & $(18.1)$ & \\
\hline & always & 5 & $(1.9)$ & 7 & $(2.7)$ & \\
\hline & missing & 2 & $(0.8)$ & 3 & $(1.2)$ & \\
\hline \multirow[t]{5}{*}{ Difficulty concentrating } & none & 98 & $(37.7)$ & 7 & $(18.1)$ & $<0.001$ \\
\hline & rarely & 80 & $(30.8)$ & 109 & $(41.9)$ & \\
\hline & frequently & 70 & $(26.9)$ & 85 & $(32.7)$ & \\
\hline & always & 10 & $(3.8)$ & 16 & $(6.2)$ & \\
\hline & missing & 2 & $(0.8)$ & 3 & $(1.2)$ & \\
\hline \multirow[t]{5}{*}{ Lack of motivation } & none & 125 & $(48.1)$ & 88 & $(33.8)$ & $<0.001$ \\
\hline & rarely & 112 & $(43.1)$ & 112 & $(43.1)$ & \\
\hline & frequently & 14 & (5.4) & 45 & $(17.3)$ & \\
\hline & always & 4 & $(1.5)$ & 10 & (3.8) & \\
\hline & missing & 5 & $(1.9)$ & 5 & (1.9) & \\
\hline \multirow[t]{5}{*}{ Sensitivity to stress } & none & 62 & $(23.8)$ & 42 & $(16.2)$ & 0.005 \\
\hline & rarely & 119 & $(45.8)$ & 110 & $(42.3)$ & \\
\hline & frequently & 48 & $(18.5)$ & 76 & $(29.2)$ & \\
\hline & always & 19 & $(7.3)$ & 19 & (7.3) & \\
\hline & missing & 12 & $(4.6)$ & 13 & $(5.0)$ & \\
\hline
\end{tabular}

Number (\%), ns: not significant. 
feeling of sufficient sleep, refreshed feeling after waking up and wake-up time on a weekday. The proportion of students who had less sleeping hours, less feeling of sufficient sleep and less refreshing feeling after waking up after starting use smartphone were higher than those before using smartphones (Table 3).

Table 3. Differences in sleeping status before and after starting to use smartphones.

\begin{tabular}{|c|c|c|c|c|c|c|}
\hline \multirow{3}{*}{$\begin{array}{l}\text { Time spent using } \\
\text { smartphones before } \\
\text { sleeping }\end{array}$} & \multirow[b]{2}{*}{$<30 \min$} & \multicolumn{2}{|c|}{$\begin{array}{l}\text { Before using } \\
\text { smartphones }\end{array}$} & \multicolumn{2}{|c|}{$\begin{array}{l}\text { After starting to } \\
\text { use smartphones }\end{array}$} & \multirow{2}{*}{$\begin{array}{l}\text { P value } \\
<0.001\end{array}$} \\
\hline & & 117 & $(45.0)$ & 52 & $(20.0)$ & \\
\hline & $30 \mathrm{~min}-1 \mathrm{hr}$ & 78 & $(30.0)$ & 95 & $(36.5)$ & \\
\hline & $1-2 \mathrm{hrs}$ & 35 & $(13.5)$ & 76 & $(29.2)$ & \\
\hline & $2-4$ hrs & 11 & $(4.2)$ & 31 & (11.9) & \\
\hline & $5 \mathrm{hrs}$ & 2 & $(0.8)$ & 4 & $(1.5)$ & \\
\hline & missing & 17 & $(6.5)$ & 2 & $(0.8)$ & \\
\hline \multirow[t]{5}{*}{ Bedtime } & before 22 o'clock & 8 & $(3.1)$ & 2 & $(0.8)$ & $<0.001$ \\
\hline & 22 - 24 o'clock & 139 & $(53.5)$ & 70 & $(26.9)$ & \\
\hline & 24 - 2 o'clock & 106 & $(40.8)$ & 174 & $(66.9)$ & \\
\hline & after 2 o'clock & 2 & $(0.8)$ & 14 & $(5.4)$ & \\
\hline & missing & 5 & (1.9) & 0 & $(0.0)$ & \\
\hline \multirow[t]{6}{*}{ Sleeping hours } & $<5 \mathrm{hrs}$ & 14 & $(5.4)$ & 32 & $(12.3)$ & $<0.001$ \\
\hline & $5-6 \mathrm{hrs}$ & 89 & $(34.2)$ & 127 & $(48.8)$ & \\
\hline & $6-7 \mathrm{hrs}$ & 108 & $(41.5)$ & 86 & $(33.1)$ & \\
\hline & $7-8$ hrs & 40 & $(15.4)$ & 13 & $(5.0)$ & \\
\hline & $>8 \mathrm{hrs}$ & 3 & $(1.2)$ & 1 & $(0.4)$ & \\
\hline & missing & 6 & $(2.3)$ & 1 & $(0.4)$ & \\
\hline \multirow{4}{*}{$\begin{array}{c}\text { Feeling of sufficient } \\
\text { sleep }\end{array}$} & yes & 127 & $(48.8)$ & 82 & $(31.5)$ & $<0.001$ \\
\hline & no & 56 & $(21.5)$ & 98 & $(37.7)$ & \\
\hline & neither & 68 & $(26.2)$ & 75 & $(28.8)$ & \\
\hline & missing & 9 & $(3.5)$ & 5 & $(1.9)$ & \\
\hline \multirow{4}{*}{$\begin{array}{l}\text { Refreshing feeling after } \\
\text { waking up }\end{array}$} & yes & 86 & $(33.1)$ & 57 & $(21.9)$ & 0.008 \\
\hline & no & 97 & $(37.3)$ & 126 & $(48.5)$ & \\
\hline & neither & 65 & $(25.0)$ & 68 & $(26.2)$ & \\
\hline & missing & 12 & $(4.6)$ & 9 & $(3.5)$ & \\
\hline \multirow{5}{*}{$\begin{array}{l}\text { Wake-up time on a } \\
\text { weekday }\end{array}$} & 5 - 6 o'clock & 22 & $(8.5)$ & 24 & $(9.2)$ & 0.031 \\
\hline & 6 - 7 o'clock & 172 & $(66.2)$ & 142 & $(54.6)$ & \\
\hline & 7 - 8 o'clock & 57 & (21.9) & 85 & $(32.7)$ & \\
\hline & after 8 o'clock & 4 & $(1.5)$ & 6 & $(2.3)$ & \\
\hline & missing & 5 & $(1.9)$ & 3 & $(1.2)$ & \\
\hline \multirow{5}{*}{$\begin{array}{c}\text { Wake-up time on a } \\
\text { holiday }\end{array}$} & 5 - 7 o'clock & 9 & $(3.5)$ & 12 & $(4.6)$ & ns \\
\hline & 7 - 9 o'clock & 114 & $(43.8)$ & 108 & $(41.5)$ & \\
\hline & 9 - 11 o'clock & 109 & $(41.9)$ & 112 & $(43.1)$ & \\
\hline & after 11 o'clock & 23 & $(8.8)$ & 25 & $(9.6)$ & \\
\hline & missing & 5 & (1.9) & 3 & $(1.2)$ & \\
\hline
\end{tabular}

Number (\%), ns: not significant. 


\subsection{Differences in Premenstrual Symptoms before and after Starting to Use Smartphones}

As shown in Table 4, regarding premenstrual symptoms, the proportion of students without fatigue decreased from $29.2 \%$ before using smartphones to $23.8 \%$ after starting to use smartphones, while the proportion who felt fatigue to some extent or severe increased from $25.8 \%$ to $33.1 \%$ and from $9.2 \%$ to $12.3 \%$, respectively. The proportion of students with physical symptoms such as fatigue before menstruation was significantly higher after starting to use smartphones. The proportions of students with irritability and depressive feeling as emotional premenstrual symptoms showed tendencies to be higher after starting to use smartphones.

\subsection{Differences in Menstrual Pain before and after Starting to Use Smartphones}

The proportion of students without headache and low back pain during menstruation decreased from $35.0 \%$ before using smartphones to $30.4 \%$ after starting to use smartphones, while the proportion with pain to some extent or severe increased from $27.7 \%$ to $29.2 \%$ and $5.8 \%$ to $7.3 \%$, respectively (Table 5 ). The proportion of students with headache and low back pain during menstruation were significantly higher after starting to use smartphones.

\subsection{Strategies for Coping with Various Symptoms}

Strategies used to cope with various symptoms caused by using smartphones were decreasing the duration of use (13.4\% of the students), frequent breaks (10.2\%), applying eye lotion (16.3\%), using protective eyeglasses (4.3\%), using in a place with sufficient brightness (12.9\%), not using before sleeping (7.9\%), visiting hospitals $(0.4 \%)$, doing eye massages $(8.6 \%)$ or eye exercises $(4.1 \%)$, viewing the screen from a distance and using with eyes closed (11.3\%).

\section{Discussion}

In the present study, we confirmed that the proportions of students who had deterioration of ocular symptoms increased, and there were significant differences in eyestrain, posture, stiffness of the neck, back and shoulders, and level of outdoor activity on a holiday before and after starting to use smartphones. Previous studies revealed that VDT users have increased risks for ocular, musculoskeletal, and mental health problems [5] [6] [7] [18] [19] [20]. For psychological symptoms, it has been reported that psychological distress was related to maladaptive use of both the Internet and mobile phones [21]. It was shown that there is a negative association between excessive smartphones use and psychological well-being [9] [10]. We found that the proportions of students with psychological conditions such as difficulty concentrating, lack of motivation and sensitivity to stress increased after starting to use smartphones.

We showed that the proportions of students with sleep disturbance increased 
Table 4. Differences in premenstrual symptoms before and after starting to use smartphones.

\begin{tabular}{|c|c|c|c|c|c|c|}
\hline \multirow[b]{2}{*}{ Irritability } & \multirow[b]{2}{*}{ None } & \multicolumn{2}{|c|}{$\begin{array}{l}\text { Before using } \\
\text { smartphones }\end{array}$} & \multicolumn{2}{|c|}{$\begin{array}{l}\text { After starting to use } \\
\text { smartphones }\end{array}$} & \multirow{2}{*}{$\begin{array}{c}\text { P value } \\
0.053\end{array}$} \\
\hline & & 80 & $(30.8)$ & 67 & $(25.8)$ & \\
\hline & A little & 97 & $(37.3)$ & 94 & $(36.2)$ & \\
\hline & To some extent & 58 & $(22.3)$ & 73 & $(28.1)$ & \\
\hline & Severe & 15 & $(5.8)$ & 21 & $(8.1)$ & \\
\hline & Missing & 10 & $(3.8)$ & 5 & (1.9) & \\
\hline \multirow[t]{5}{*}{ Depressed mood } & None & 86 & $(33.1)$ & 75 & $(28.8)$ & 0.054 \\
\hline & A little & 82 & $(31.5)$ & 74 & $(28.5)$ & \\
\hline & To some extent & 55 & $(21.2)$ & 69 & $(26.5)$ & \\
\hline & Severe & 24 & $(9.2)$ & 34 & $(13.1)$ & \\
\hline & Missing & 13 & $(5.0)$ & 8 & (3.1) & \\
\hline \multirow[t]{5}{*}{ Emotional instability } & None & 137 & $(52.7)$ & 126 & $(48.5)$ & 0.118 \\
\hline & A little & 64 & $(24.6)$ & 64 & $(24.6)$ & \\
\hline & To some extent & 32 & $(12.3)$ & 37 & $(14.2)$ & \\
\hline & Severe & 18 & $(6.9)$ & 29 & $(11.2)$ & \\
\hline & Missing & 9 & (3.5) & 4 & (1.5) & \\
\hline \multirow{5}{*}{$\begin{array}{c}\text { Difficulty } \\
\text { concentrating }\end{array}$} & None & 111 & $(42.7)$ & 99 & $(38.1)$ & 0.142 \\
\hline & A little & 95 & $(36.5)$ & 99 & $(38.1)$ & \\
\hline & To some extent & 32 & $(12.3)$ & 40 & $(15.4)$ & \\
\hline & Severe & 11 & $(4.2)$ & 15 & $(5.8)$ & \\
\hline & Missing & 11 & $(4.2)$ & 7 & $(2.7)$ & \\
\hline \multirow{5}{*}{$\begin{array}{l}\text { Breast distension and } \\
\text { tenderness }\end{array}$} & None & 99 & $(38.1)$ & 87 & $(33.5)$ & 0.150 \\
\hline & A little & 68 & $(26.2)$ & 67 & $(25.8)$ & \\
\hline & To some extent & 64 & $(24.6)$ & 76 & $(29.2)$ & \\
\hline & Severe & 20 & $(7.7)$ & 24 & $(9.2)$ & \\
\hline & Missing & 9 & $(3.5)$ & 6 & $(2.3)$ & \\
\hline \multirow[t]{5}{*}{ Fatigue } & None & 76 & $(29.2)$ & 62 & $(23.8)$ & 0.028 \\
\hline & A little & 83 & $(31.9)$ & 76 & $(29.2)$ & \\
\hline & To some extent & 67 & $(25.8)$ & 86 & $(33.1)$ & \\
\hline & Severe & 24 & $(9.2)$ & 32 & $(12.3)$ & \\
\hline & Missing & 10 & $(3.8)$ & 4 & (1.5) & \\
\hline \multirow[t]{5}{*}{ Rough skin } & None & 93 & $(35.8)$ & 86 & $(33.1)$ & 0.282 \\
\hline & A little & 76 & $(29.2)$ & 74 & $(28.5)$ & \\
\hline & To some extent & 60 & $(23.1)$ & 71 & $(27.3)$ & \\
\hline & Severe & 22 & (8.5) & 25 & (9.6) & \\
\hline & Missing & 9 & (3.5) & 4 & (1.5) & \\
\hline
\end{tabular}




\begin{tabular}{|c|c|c|c|c|c|c|}
\hline \multicolumn{7}{|l|}{ Continued } \\
\hline \multirow{5}{*}{$\begin{array}{c}\text { Increase in body } \\
\text { weight }\end{array}$} & None & 155 & $(59.6)$ & 146 & $(56.2)$ & \multirow[t]{5}{*}{0.171} \\
\hline & A little & 66 & $(25.4)$ & 71 & $(27.3)$ & \\
\hline & To some extent & 25 & $(9.6)$ & 34 & (13.1) & \\
\hline & Severe & 3 & $(1.2)$ & 5 & $(1.9)$ & \\
\hline & Missing & 11 & $(4.2)$ & 4 & $(1.5)$ & \\
\hline \multirow[t]{5}{*}{ Hypersomnia } & None & 133 & $(51.2)$ & 124 & $(47.7)$ & \multirow[t]{5}{*}{0.15} \\
\hline & A little & 47 & $(18.1)$ & 46 & $(17.7)$ & \\
\hline & To some extent & 50 & $(19.2)$ & 52 & $(20.0)$ & \\
\hline & Severe & 18 & $(6.9)$ & 31 & (11.9) & \\
\hline & Missing & 12 & $(4.6)$ & 7 & $(2.7)$ & \\
\hline
\end{tabular}

Number (\%).

Table 5. Differences in menstrual pain before and after starting to use smartphones.

\begin{tabular}{ccccccc}
\hline & & \multicolumn{2}{l}{$\begin{array}{c}\text { Before using } \\
\text { smartphones }\end{array}$} & $\begin{array}{c}\text { After starting to use } \\
\text { smartphones }\end{array}$ & P value \\
\hline Abdominal pain & None & 67 & $(25.8)$ & 56 & $(21.5)$ & 0.177 \\
& A little & 65 & $(25.0)$ & 62 & $(23.8)$ & \\
& To some extent & 79 & $(30.4)$ & 94 & $(36.2)$ & \\
& Severe & 37 & $(14.2)$ & 40 & $(15.4)$ & \\
Headache and low & Missing & 12 & $(4.6)$ & 8 & $(3.1)$ & \\
back pain & None & 91 & $(35.0)$ & 79 & $(30.4)$ & $<0.001$ \\
& A little & 63 & $(24.2)$ & 74 & $(28.5)$ & \\
& To some extent & 72 & $(27.7)$ & 76 & $(29.2)$ & \\
& Severe & 15 & $(5.8)$ & 19 & $(7.3)$ & \\
& Missing & 19 & $(7.3)$ & 12 & $(4.6)$ & \\
\hline
\end{tabular}

Number (\%).

after starting to use smartphones. It has been reported that "smartphone use after lights out" was related to sleep disorders and life rhythms [22], and disturbance of circadian rhythm and sleep deficiency affect various psychological functions [23]. Moreover, disturbed sleep habituation including delayed bedtime and insufficient sleeping hours was associated with depression and irritability [24]. The use of smartphones may cause poor psychological conditions through disturbances of circadian rhythm and sleeping.

With respect to premenstrual symptoms, we found that the proportion of students with fatigue before menstruation was higher than after starting to use smartphones and the proportion of students with irritability and depressive feeling as emotional premenstrual symptoms tended to be higher than after starting to use smartphones. It has been reported that factors such as insufficient stress coping, insufficient sleep, menstrual distress and smoking habit indirectly 
cause PMS [25]. Since it has been reported that decrease in melatonin secretion in the luteal phase was found in women with PMS [16], premenstrual symptoms may be associated with melatonin level. Also, longer daily VDT use might result in deterioration of mental health status [20]. Deterioration of symptoms such as delayed wake-up time on a weekday, difficulty concentrating and sensitivity to stress after using a VDT for a long time may be associated with deterioration of psychological premenstrual symptoms. In addition, deterioration of sleep disturbances and difficulty concentrating caused by smartphones use may be involved in aggravation of physical premenstrual symptoms. Attention must be given to psychological distress and sleep disturbance, particularly before menstruation, to prevent deterioration of premenstrual symptoms. It has been reported that exposure to low-intensity blue light in the evening elicits drowsiness and suppression of energy metabolism the following morning [26]. Exposure to blue light by using smartphones may induce a decrease in metabolism in the body since an increase in body weight was found before menstruation.

We found that the proportion of students with headache and low back pain during menstruation was significantly higher than after starting to use smartphones. The etiology of primary dysmenorrhea includes an excess or imbalance in the secretion of prostaglandins (PGs) from the endometrium during menstruation. It has been reported that an increase in PGE2 metabolite levels in response to sleep loss was associated with spontaneous pain complaints [27]. Also, there was a relationship between sleeping hours and menstrual pain [28] and sympathetic nerve activities were higher during the luteal phase and that fluctuation in sympathetic nerve activities was increased by exposure to white light-emitting diodes [29]. The threshold for sensitivity to stress as well as for pain stimulation may be changed by using smartphones.

The students have done variety of strategies for coping with symptoms that occurred by using smartphones in the present study. Appropriate smartphones use and coping with VDT-related symptoms are important to reduce the occurrence of not only VDT-related symptoms but also menstruation-related symptoms. VDT devices including smartphones will be used more widely in the future. For their adverse effects, young women should avoid excessive use of them. Parents, teachers and medical staff should understand and educate children and students about the adverse effects of using smartphones. In addition, further study will be needed for identifying strategies to reduce the smartphone-related symptoms or negative health conditions in students.

There are limitations in this study. First, this study is cross-sectional survey that has recall bias and the period to start using smartphones varies by each student. Physical and psychological symptoms might vary in each menstrual cycle. The period after starting to use smartphones is rather short since smartphones have become popular only in the past few years. Thus, the effects of smartphones on physical and psychological conditions, sleeping status and menstruation-related symptoms over a long period should be investigated using a pros- 
pective study. Second, some students may have medical histories such as gynecological diseases, and it might influence to our results such as menstrual pain. Third, detail of conditions on smartphones use, which is size of screen, degree of the screen light, the purpose of use smartphone, duration of using it might influence of results. Finally, objective evaluation by using a VAS score, and determination of sleeping status by using actigraphy are needed.

\section{Conclusion}

In conclusion, there were significant differences in eyestrain, posture, stiffness of neck, back and shoulders, and level of outdoor activity, difficulty concentrating, lack of motivation, and sensitivity to stress, fatigue before menstruation and headache/low back pain during menstruation before and after starting to use smartphones. Young women should refrain from using smartphones if they have VDT-related symptoms, disturbance of sleep pattern and menstruation-related symptoms before and during menstruation.

\section{Acknowledgements}

The authors extend their thanks to the participants in this study.

\section{Conflicts of Interest}

The authors declare no conflicts of interest regarding the publication of this paper.

\section{References}

[1] The Ministry of Internal Affairs and Communications (2018) Information and Communications in Japan, White Paper 2018.

http://www.soumu.go.jp/johotsusintokei/whitepaper/eng/WP2018/2018-index.html

[2] The Ministry of Internal Affairs and Communications (2018) Jyoho Tsushin Hakusho, Heisei 30 nen-do. (In Japanese)

http://www.soumu.go.jp/johotsusintokei/whitepaper/ja/h30/pdf/n4200000.pdf

[3] Moon, J.H., Kim, K.W. and Moon, N.J. (2016) Smartphone Use Is a Risk Factor for Pediatric Dry Eye Disease According to Region and Age: A Case Control Study. BMC Ophthalmology, 16, 188. https://doi.org/10.1186/s12886-016-0364-4

[4] Choi, J.H., Li, Y., Kim, S.H., Jin, R., Kim, Y.H., Choi, W., You, I.C. and Yoon, K.C. (2018) The Influences of Smartphone Use on the Status of the Tear Film and Ocular Surface. PLoS ONE, 13, e0206541. https://doi.org/10.1371/journal.pone.0206541

[5] Gerr, F., Marcus, M. and Ortiz, D.J. (1996) Methodological Limitations in the Study of Video Display Terminal Use and Upper Extremity Muscloskeletal Disorders. American Journal of Industrial Medicine, 29, 649-656. https://doi.org/10.1002/(SICI)1097-0274(199606)29:6<649::AID-AJIM9>3.0.CO;2-E

[6] Hannan, L.M., Montelih, C.P., Gerr, F., Kleinbaum, D.G. and Marcus, M. (2005) Job Strain and Risk of Muscloskeletal Symptoms among a Prospective Cohort of Occupational Computer Users. Scandinavian Journal of Work, Environment \& Health, 31, 375-386. https://doi.org/10.5271/sjweh.921

[7] Smith, M.J. (1997) Psychosocial Aspects of Working with Video Display Terminals 
(VDTs) and Employee Physical and Mental Health. Ergonomics, 40, 1002-1015. https://doi.org/10.1080/001401397187568

[8] Lee, M., Hong, Y., Lee, S., Won, J., Yang, J., Park, S., Chang, K.T. and Hong, Y. (2015) The Effects of Smartphone Use on Upper Extremity Muscle Activity and Pain Threshold. Journal of Physical Therapy Science, 27, 1743-1745. https://doi.org/10.1589/jpts.27.1743

[9] Kim, H.J., Min, J.Y., Kim, H.J. and Min, K.B. (2017) Association between Psychological and Self-Assessed Health Status and Smartphone Overuse among Korean College Students. Journal of Mental Health, 28, 11-16. https://doi.org/10.1080/09638237.2017.1370641

[10] Tangmunkongvorakul, A., Musumari, P.M., Thongpibul, K., Srithanaviboonchai, K., Techasrivichien, T., Suguimoto, S.P., Ono-Kihara, M. and Kihara, M. (2019) Association of Excessive Smartphone Use with Psychological Well-Being among University Students in Chiang Mai, Thailand. PLoS ONE, 14, e0210294. https://doi.org/10.1371/journal.pone.0210294

[11] Higuchi, S., Motohashi, Y., Liu, Y., Ahara, M. and Kaneko, Y. (2003) Effects of VDT Tasks with a Bright Display at Night on Melatonin, Core Temperature, Heart Rate, and Sleepiness. Journal of Applied Physiology, 94, 1773-1776. https://doi.org/10.1152/japplphysiol.00616.2002

[12] Chang, A.M., Aeschbach, D., Duffy, J.F. and Czeisler, C.A. (2015) Evening Use of Light-Emitting eReaders Negatively Affects Sleep, Circadian Timing, and Next-Morning Alertness. Proceedings of the National Academy of Sciences of the United States of America, 112, 1232-1237. https://doi.org/10.1073/pnas.1418490112

[13] Scheer, F.A.J.L., Hilton, M.F., Mantzoros, C.S. and Shea, S.A. (2009) Adverse Metabolic and Cardiovascular Consequences of Circadian Misalignment. Proceedings of the National Academy of Sciences of the United States of America, 106, 4453-4458. https://doi.org/10.1073/pnas.0808180106

[14] Wu, L. and Reddy, A.B. (2013) Disrupting Rhythms: Diet-Induced Obesity Impairs Diurnal Rhythms in Metabolic Tissues. Diabetes, 62, 1829-1830. https://doi.org/10.2337/db13-0353

[15] Cheung, I.N., Zee, P.C., Shalman, D., Malkani, R.G., Kang, J. and Reid, K.J. (2016) Morning and Evening Blue-Enriched Light Exposure Alters Metabolic Function in Normal Weight Adults. PLOS ONE, 11, e0155601. https://doi.org/10.1371/journal.pone.0155601

[16] Parry, B.L., Berga, S.L., Kripke, D.F., Klauber, M.R., Laughlin, G.A., Yen, S.S. and Gilli, J.C. (1990) Altered Waveform of Plasma Nocturnal Melatonin Secretion in Premenstrual Depression. Archives of General Psychiatry, 47, 1139-1146. https://doi.org/10.1001/archpsyc.1990.01810240059010

[17] Shibui, K., Uchiyama, M., Okawa, M., Kudo, Y., Kim, K., Liu, X., Kamei, Y., Hayakawa, T., Akamatsu, T., Ohta, K. and Ishibashi, K. (2000) Diurnal Fluctuation of Sleep Propensity and Hormonal Secretion across the Menstrual Cycle. Biological Psychiatry, 48, 1062-1068. https://doi.org/10.1016/S0006-3223(00)00912-4

[18] Jaschinski, W., Heuer, H. and Kylian, H. (1998) Preferred Position of Visual Displays Relative to the Eyes: A Field Study of Visual Strain and Individual Differences. Ergonomics, 41, 1034-1049. https://doi.org/10.1080/001401398186586

[19] Tsubota, K. and Nakamori, K. (1993) Dry Eyes and Video Display Terminals. New England Journal of Medicine, 328, 584. https://doi.org/10.1056/NEJM199302253280817

[20] Ye, Z., Abe, Y., Kusano, Y., Takamura, N., Eida, K., Takemoto, T. and Aoyagi, K. 
(2007) The Influence of Visual Display Terminal Use on the Physical and Mental Conditions of Administrative Staff in Japan. Journal of Physiological Anthropology, 26, 69-73. https://doi.org/10.2114/jpa2.26.69

[21] Beranuy, M., Oberst, U., Carbonell, X. and Chamarro, A. (2009) Problematic Internet and Mobile Phone Use and Clinical Symptoms in College Students: The Role of Emotional Intelligence. Computers in Human Behavior, 25, 1182-1187. https://doi.org/10.1016/j.chb.2009.03.001

[22] Monma, T., Ando, A., Asanuma, T., Yoshitake, Y., Yoshida, G., Miyazawa, T., Ebine, N., Takeda, S., Omi, N., Satoh, M., Tokuyama, K. and Takeda, F. (2018) Sleep Disorder Risk Factors among Student Athletes. Sleep Medicine, 44, 76-81. https://doi.org/10.1016/j.sleep.2017.11.1130

[23] Hashimoto, T. (2004) Sleep in Contemporary Society and Work Environment: The State of Child Sleep. Shikoku Acta Medica, 60, 14-19.

[24] Watanabe, A., Kasamaki, J. and Miyanishi, K. (2016) Relationship between Lifestyle and Subjective Symptoms, Indefinite Complaints, and Cumulative Fatigue Symptoms in Junior High School Students. A Systematic Review. The Journal of Child Health, 75, 365-375.

[25] Watanabe, K., Toda, M., Nishiumi, H., Okada, K. and Okumura, Y. (2014). Health Care Analysis of Physical Stress and Personal Lifestyle, as Socio-Medical Backgrounds, in Reproductive-Age Women with Premenstrual Syndrome. Japanese Journal of Maternal Health, 52, 437-443.

[26] Kayaba, M., Iwayama, K., Ogata, H., Seya, Y., Kiyono, K., Satoh, M. and Tokuyama, K. (2014) The Effect of Nocturnal Blue Light Exposure from Light-Emitting Diodes on Wakefulness and Energy Metabolism the Following Morning. Environmental Health and Preventive Medicine, 19, 354-361. https://doi.org/10.1007/s12199-014-0402-x

[27] Haack, M., Lee, E., Cohen, D.A. and Mullington, J.M. (2009) Activation of the Prostaglandin System in Response to Sleep Loss in Healthy Humans: Potential Mediator of Increased Spontaneous Pain. Pain, 145, 136-141. https://doi.org/10.1016/j.pain.2009.05.029

[28] Saitou, C. and Nishiwaki, M. (2005) Relationship between Menstruation Pattern and Premenstrual and Menstrual Discomfort Symptoms, and Coping Methods. Yamagata Journal of Health Sciences, 8, 53-63.

[29] Matsumoto, K., Matsuda, M., Miyata, F., Karahi, S, Ichihara, K. and Hirano, H. (2006) The Effects of Bright Light Therapy on Autonomic Nervous Activities during Menstrual Cycle. Yamaguchi Medical Journal, 55, 167-172.

https://doi.org/10.2342/ymj.55.167 


\section{Appendix}

\section{Questionnaire}

\section{Personal Information}

(1) Your age?

(2) When did you start smartphone use?

(3) How many hours do you use smartphone in a day?

\section{year old}

1. Elementary school

2. Junior high school

3. High school

4. University and after

1. Less than 3 hours

2. $3 \sim 5$ hours

3. $5 \sim 7$ hours

4. $7 \sim 9$ hours

5. More than 9 hours

Please circle the most applicable number in the questions below.

\section{Before having smartphone}

After having smartphone

\section{About your lifestyle and physical condition}

(4) How is your appetite?

1. Very good
2. Good
3. Average
4. Poor

(5) How has your weight changed since having your smartphone?

(6) Do you have constipation?

1. Severe
2. To some extent
3. A little
4. None
1. Severe
2. To some extent
3. A little
4. None

(8) Did your eyesight become worse after having your smartphone?

(9) Does the smartphone use cause the symptoms on the right? (Multiple answers allowed)
1. Very good
2. Good
3. Average
4. Poor

1. Increased by $>10 \mathrm{~kg}$ per year or $>3 \mathrm{~kg}$ per month.

2 . Decreased by $>10 \mathrm{~kg}$ per year or $>3 \mathrm{~kg}$ per month

3. Changes (not applicable to 1 or 2 )

4. No change

1. Severe

2. To some extent

3. A little

4. None

1. Severe

2. To some extent

3. A little

4. None

1. Severe

2. To some extent

3. A little

4. None

1. Dizzy

2. Tinnitus

3. Nausea

4. Headache

5. Dry eyes 


\section{Continued}

(10) How is your posture? (bending forward, stoop, constant looking down)
1. Good
2. Bad
3. Can't say
1. Severe
2. To some extent
3. A little
4. None

(12) Did you spend more time sitting or sleeping after having smartphone?

(13) How long do you spend in your room on holidays?
1. Most of the time
2. Long hours
3. A few hours
4. A little time

(14) Did you ever notice your physical fitness become worse after having smartphone?
1. Good
2. Bad
3. Can't say
1. Severe
2. To some extent
3. A little
4. None
1. Yes
2. No
3. Can't say

1. Most of the time

2. Long hours

3. A few hours

4. A little time

1. Very

2. To some extent

3. A little

4. None

\section{About sleep}

(15) Time spent using smartphones before actual sleeping?

*Please fill in the "before having smartphone" for conventional mobile phone use
1. $<30 \mathrm{~min}$
2. $30 \mathrm{~min} \sim 1 \mathrm{hr}$
3. $1 \sim 2$ hrs

$$
\text { 5. }>5 \text { hrs }
$$

1. $<30 \mathrm{~min}$

2. $30 \mathrm{~min} \sim 1 \mathrm{hr}$

3. $1 \sim 2 \mathrm{hrs}$

4. $2 \sim 4$ hrs

5. $>5 \mathrm{hrs}$

(16) When is your bedtime?

1. Before 22 o'clock

2. $22 \sim 24$ o'clock

3. $24 \sim 2$ o'clock

4. $2 \sim 4$ o'clock

5. After 4 o'clock

1. $<5 \mathrm{hrs}$

$2.5 \sim 6 \mathrm{hrs}$

3. $6 \sim 7 \mathrm{hrs}$

4. $7 \sim 8 \mathrm{hrs}$

5. $>8 \mathrm{hrs}$

(18) Do you have feeling of sufficient sleep every day? 1. Yes

\section{No \\ 3. Can't say}

(19) Do you have problems with sleep as specified on 1 . I can't sleep well the right? (Multiple answers allowed)
1. Before 22 o'clock

2. $22 \sim 24$ o'clock

3. $24 \sim 2$ o'clock

4. $2 \sim 4$ o'clock

5. After 4 o'clock

1. $<5$ hrs

2. $5 \sim 6 \mathrm{hrs}$

3. $6 \sim 7 \mathrm{hrs}$

4. $7 \sim 8 \mathrm{hrs}$

5. $>8 \mathrm{hrs}$

1. Yes

2. No

3. Can't say

1. I can't sleep well

2. Superficial sleep

3. I wake up many times at night

4. Short sleep time

5. Still tired even after sleep

6. No problem 


\section{Continued}

(20) Do you feel refreshed when waking up in the morning?

(21) Your wake-up time on weekdays?

(22) Your wake-up time on holidays?

(23) How long does it take to actually wake up after initial waking up in the morning?

1. Yes

2. No

3. Can't say

1. $5 \sim 6$ o'clock

2. $6 \sim 7$ o'clock

3. $7 \sim 8$ o'clock

4. Later than 8 o'clock

1. $5 \sim 7$ o'clock

2. $7 \sim 9$ o'clock

3. $9 \sim 11$ o'clock

4. Later than 11 o'clock

1. $<30 \mathrm{~min}$

2. $30 \sim 60 \mathrm{~min}$

3. $>60 \mathrm{~min}$

IV. About mental issues

(24) Are you irritable?

(26) Do you feel your motivation level reduced?

(27) Is it easy to feel stress?

(25) Does your concentration level easily reducing?
2. Frequently
3 . Rarely
4. None
1. Always
2. Frequently
3. Rarely
4. None

1. Always
1. Yes

2. No

3. Can't say

1. $5 \sim 6$ o'clock

2. $6 \sim 7$ o'clock

3. $7 \sim 8$ o'clock

4. Later than 8 o'clock

1. $5 \sim 7$ o'clock

2. $7 \sim 9$ o'clock

3. $9 \sim 11$ o'clock

4. Later than 11 o'clock

1. $<30 \mathrm{~min}$

2. $30 \sim 60 \mathrm{~min}$

3. $>60 \mathrm{~min}$

1. Always

2. Frequently

3 . Rarely

4. None

1. Always

2. Frequently

3. Rarely

4. None

1. Always

2. Frequently

3. Rarely

4. None

1. Always

2. Frequently

3. Rarely

4. None

\section{About menstruation}

(28) How many days does your menstruation come?

(29) Have you had no menstruation for more than three months?

(30) Are you irritable before menstruation?
1. Up to 24 days
2. $25 \sim 38$ days, regularly
3. 39 days or longer
1. Yes
3. Can't say
1. Severe
2. To some extent
3. A little
4. None

1. Up to 24 days

2. $25 \sim 38$ days, regularly

3. 39 days or longer

1. Yes

2. No

3. Can't say

1. Severe

2. To some extent

3. A little 


\section{Continued}

(31) Do you feel depressed before menstruation? before menstruation?

(34) Do you feel breast tension and pain before menstruation?

(35) Do you feel fatigue before menstruation?

(36) Do you get rough skin and acne before menstruation?

(38) Do you have sleep related symptoms such as drowsiness and insomnia before menstruation?

(39) Do you have an abdominal pain during menstruation?

(40) Do you have a headache or backache during menstruation?

(41) What is your menstrual volume after having smartphone?

\author{
1. Severe \\ 2. To some extent \\ 3. A little \\ 4. None
}

1. Severe

2. To some extent

3. A little

4. None

1. Severe

2. To some extent

3. A little

4. None

1. Severe

2. To some extent

3. A little

4. None

1. Severe

2. To some extent

3. A little

4. None

1. Severe

2. To some extent

3. A little

4. None

1. Severe

2. To some extent

3. A little

4. None

1. Severe

2. To some extent

3. A little

4. None

1. Severe

2. To some extent

3. A little

4. None

1. Severe

2. To some extent

3. A little

4. None
1. Severe

2. To some extent

3. A little

4. None

1. Severe

2. To some extent

3. A little

4. None

1. Severe

2. To some extent

3. A little

4. None

1. Severe

2. To some extent

3. A little

4. None

1. Severe

2. To some extent

3. A little

4. None

1. Severe

2. To some extent

3. A little

4. None

1. Severe

2. To some extent

3. A little

4. None

1. Severe

2. To some extent

3. A little

4. None

1. Severe

2. To some extent

3. A little

4. None

1. Severe

2. To some extent

3. A little

4. None

1. Increased

2. Decreased

3. No change 


\section{Continued}

(42) Do you have any countermeasure against negative health conditions following use of a smartphone (multiple answers allowed)
1. Decreasing the duration of use
2. Frequent breaks
3. Applying eye lotion
4. Using protective eyeglasses
5. Using in a place with sufficient brightness
6. Viewing the screen from a distance
7. Not using before sleeping
8. Visiting hospitals
9. Taking medications
10. Doing eye massages
11. Looking far away
12. Using with eyes closed
13. Eye exercises

\section{Thank you.}

